\title{
Exploring Scope for Breeding of Rice Varieties for Efficient Ethanol Production without Compromising Seed Yield
}

\author{
Swapan K. Tripathy ${ }^{*}$, Jayashree Kar, Bhaskar Chakma, Suraj K. Behera, \\ Asit P. Dash, Arjun Prusty and Dayanidhi Mishra
}

Department of Agricultural Biotechnology, College of Agriculture, OUAT, Bhubaneswar-751003 (Odisha), India

*Corresponding author

\section{A B S T R A C T}

Keywords

Rice straw, Ethanol production, Genetic basis of cellulosic components

Article Info

Accepted: 04 April 2018 Available Online: 10 May 2018
Rice straw being rich in cellulose and plentily available, it can serve as the chief renewable biomass resource for biofuel production. Several protocols are now available for efficient recovery of ethanol from cellulosic substrates of rice straw. Rice varieties showing high lignocellulosic straw biomass inherently reveal low harvest index and consequently low grain yield potential. There is an urgent need to reorient the breeding strategies for efficient ethanol production without compromising seed yield. The authors reviewed the scope of rice straw for biofuel (ethanol) production and also the genetic basis for biosynthesis of lignocellulose components and their breeding perspective for development of bioenergy efficient smart varieties in rice.

\section{Introduction}

Petrochemicals are the chief inputs for transport and agricultural mechanization. India being an agrarian and second populous country next to China; petroleum becomes the lifeline for Indian economy. In recent years, climate change and energy security are the top agendas in almost all countries. Globally, rice covers about 160 million hectares with a quantum of 740 million tons grains and 730 million tons of straw (FAO, 2014). Asia alone produced 651.58 million tonnes, accounting for $90 \%$ of the world's rice output. To keep pace with the world's growing population, rice production is to be increased by $40 \%$ by 2030 (Huang et al., 2013). Rice straw is used as cattle feed, thatch of rural houses, mushroom production and rest as waste. With increasing scarcity of labour and difficulty in transport of huge bulk of rice stalks; large part of this undergoes field burning that increases the air pollution and consequently affects public health (Mussatto and Roberto, 2004). Alternatively, rice straw being an abundantly available lignocellulosic biomass (structural carbohydrates) and a non-food item, it can serve as potential substrate for biofuel 
(ethanol) production. In the present pursuit, the authors reviewed the scope of rice straw for ethanol production and also the genetic basis for biosynthesis of lignocellulose components and their breeding perspective for development of bioenergy efficient smart varieties in rice.

\section{Composition of lignocellulose components in rice straw}

Rice straw contains higher amount of cellulose (32-47\%) and hemicellulose (19-27\%) as cell wall components (Saha, 2003). Cellulose part of cell wall contains parallel arranged long fibres while, hemicelluloses make crosslinking with cellulosic fibres. Structurally, cellulose is the major component of plant cell wall and it is composed of linear chain of Dglucose linked by $\beta$ - $(1,4)$-glycosidic bonds to each other. While, hemicelluloses is a heterogeneous sugar complex of pentoses $(\beta$ D-xylose, $\alpha$-L arabinose), hexoses $(\beta$ Dmannose, $\beta$-D-glucose, $\alpha$-D galactose) (Fig. 1) and/or organic acids ( $\alpha$-D glucuronic, $\alpha$-D4-O-methyl-galacturonic and a-D-galacturonic acids). Both of these are readily fermentable by microorganism mediated hydrolytic enzymes to form ethanol. The ethanol so produced may be blended with petrol and gasoline to reduce cost of petrol. But, higher amount of lignin (5-24\%), ash (10-17\%), silica ( $75 \%$ of the ash) and potassium in rice straw are the deterrent factors for conversion of cellulose and hemicellulose to fermentable sugars. However, different pre-treatment methods are now available to make the whole process economically viable. In fact, lignin is an aromatic, amorphous and hydrophobic polymer synthesized from phenylpropanoid precursors which forms inner and outer rigid cell wall matrix. High silica content wears out the cellulosic fibres and such structural aberration interferes sugar recovery in follow -up steps. Ash content in rice straw is much higher than that in wood. Ash and potassium cause agglomeration of the components during processing; hence these seem to be barriers in conversion to sugar.

\section{Estimation of cell wall components}

Extraction of lignocellulose components is expensive and energy intensive. Rice straw treated with $\mathrm{NaOH}$ dissociates the hemicellulose component of the cell wall, while cellulose fraction is solubilised by treatment with concentrated $\mathrm{H}_{2} \mathrm{SO}_{4}$. A number of methods are now available for isolation of cellulose, hemicelluloses and lignin component in rice straw depending upon kind of hydrolysing agent used (alkali, inorganic acids, organic acids) alone or in combination with thermal treatment, temperature, duration and $\mathrm{pH}$ condition during extraction process. However, a simple and cost effective direct method (Moubasher et al., 1982) may be followed with minor modification. Air dried small pilled rice straw is boiled in ethanol for $15 \mathrm{~min}$, washed thoroughly with distilled water and kept in oven for dry weight at $40^{\circ} \mathrm{C}$ overnight, then divided into two parts in which one part is considered as A fraction. Second part of residue is refluxed at $80^{\circ} \mathrm{C}$ with $0.5 \mathrm{M}$ $\mathrm{NaOH}(100 \mathrm{ml} / \mathrm{g}$ of biomass) for $4 \mathrm{~h}$ followed by filtering and washing the residue with plentiful of distilled water until $\mathrm{pH} 7.0$, dried at $80^{\circ} \mathrm{C}$ over night and the dry weight taken as $\mathrm{B}$ fraction. A-B value is the hemicelluloses content in the rice straw. The same sample(B) is again soaked with concentrated $\mathrm{H}_{2} \mathrm{SO}_{4}$ (30 $\mathrm{ml} / \mathrm{g}$ of biomass) at room temperature for $24 \mathrm{~h}$, and then refluxed at $100^{\circ} \mathrm{C}$ for $1 \mathrm{~h}$ followed by filtering and washing the residue with distilled water until $\mathrm{pH} 7.0$, dried at $80^{\circ} \mathrm{C}$ overnight and the dry weight taken as $\mathrm{C}$ fraction. B-C value gives cellulose content while, $\mathrm{C}$ value itself is the lignin content in rice straw. However, modern analytical methods e.g., Near Infrared Spectroscopy (NIRS) and Near-field Thermal Radiation (NFTR), Fourier- transform infrared 
spectroscopy (FT-IR), Scanning electron microscope (SEM), Energy-dispersive X-ray analyzer (EDX), Thermo-gravimetry Differential Thermal Analyzer (TG-DTA) and (Gas Chromatography-Mass Spectrometry (GC-MS) can be used for rapid assessment of polysaccharide components in rice straw.

\section{Ethanol production from rice straw}

Rice straw is the cheap source of abundant lignocellulosic waste materials for ethanol production. Rice straw is grounded by several methods (ball milling, roll milling, wet disk milling etc.) prior to its pretreatment to permit enzymatic saccharification. Cellulose and hemicellulose components are required for ethanol recovery while lignin component of rice straw needs to be separated as waste material. Cellulose is first converted to fermentable sugars (glucose) by cellulase, while, hemicelluloses are hydrolysed to produce pentose sugar (xylose) and small fraction of other sugars e.g., arabinose, galactose, and mannose) by hemicellulases produced by specific microorganisms (biological saccharification). These simple sugars are fermented to produce ethanol using yeasts. Ethanol so produced is then fractionated through a series of purification steps.

\section{Pre-treatment}

Pretreatment of rice straw plays an important role to increase the efficiency of enzymatic saccharification. This allows structural loosening of cellulose and hemicelluloses (decrease the crystallinity and degrees of polymerization of cellulose) from the lignin component (Fig. 2) and thereby enhances the accessibility of the cellulosic substrate (carbohydrate polymers) for conversion to fermentable sugars in the follow-up step. A number of physical, chemical, biological and thermal pre-treatment methods and their combinations are now available. Acid digestion in dilute $\mathrm{HCl}$, sulphuric $\operatorname{acid}(0.6 \%$ $\mathrm{v} / \mathrm{v}$ ), acetic acid or formic acid, fumaric acid, maleic acid, lactic acid, oxalic acid etc. at $140^{\circ} \mathrm{C}$ is needed to solubilise hemicelluloses. Alternatively, alkali ( $\mathrm{NaOH}$ and $\mathrm{KOH})$ (Gaspar et al., 2007), hydrogen peroxide (oxidizing agent) (Hon and Shiraishi, 2001) or ammonia (Kim and Lee, 2007) may be used for the purpose. $2 \% \mathrm{NaOH}$ pretreatment for 3 hours results high total carbohydrate content while high concentration of $\mathrm{NaOH}(12 \%$ w/v) for 1 hour is best for delignification of rice straw. A two-step pretreatment of rice straw with dilute sulfuric acid and aqueous ammonia is reported to offer more efficient conversion to fermentable sugar (Kim et al., 2013). Besides, thermal treatment e.g., microwave (Xiong et al., 2000), electron beam irradiation (Jin et al., 2009), ultrasonic (Wongjewboot et $a l$. , 2010) and popping method (Wi et al., 2013) proved beneficial prior to enzymatic hydrolysis. Lu and Minoru (1993) reported radiation pretreatment of rice straw in the presence of $\mathrm{NaOH}$ solutions using an electron beam accelerator. A $0.16 \mathrm{~kW} / \mathrm{L}$ ultrasonic treatment helps in breaking of lignin and exposition of cellulose surface. Popping method offers two fold increase in surface area of rice straw than control for more accessibility to hydrolytic enzymes in the follow-up step. However, biological pretreatment using white-rot fungi (Pleurotus ostreatus) belonging to Basidiomycetes seems to be a safe, cost effective and environmentfriendly method (Taniguchi et al., 2005) for lignin removal from lignocellulose.

\section{Enzymatic saccharification}

The cellulose usually contains only glucans, whereas hemicellulose contains polymers of several sugars such as, xylan, glucan, galactan, mannan and arabinan. Readily decomposable rice straw is all time needed for higher recovery of ethanol. The saccharification step 
involves conversion of cellulose and hemicelluloses to fermentable sugars (Fig. 3). By enzymatic hydrolysis with a commercial cellulase and $\beta$-glucosidase preparation for 48 $\mathrm{h}$, about $52 \%$ holocellulose (cellulose + hemicellulose) and $44 \%$ cellulose in the pretreated rice straw were solubilised. Tricoderma koningii BTS120, Aspergillus niger BTS149, Aspergillus tubingnsis BTS83 and Penicillium roquofrti BTS12 culture filtrates are the best producer of extracellular cellulases and hemicellulases and crude enzymes in liquid culture. The concentration and rate of glucose production depends on pretreatment of rice straw, substrate concentration and cell loading with microbe filtrates. Glucose yield from rice straw by Aspergillus niger is reported to increase from 43 to $87 \%$ (Aderemi et al., 2008). Besides, the supplementation of non-cellulolytic enzymes such as xylanase, pectinase, feruloyl esterase is reported to enhance hydrolysis of lignocellulosic biomass (Tabka et al., 2006).

\section{Fermentation}

Glucose and xylose are two dominating sugars in the lignocellulosic hydrolysates produced at the saccharification step. For follow-up fermentation, two specific microorganisms are necessary for co-fermentation of these sugars at suitable temperature and duration ( $\mathrm{Fu}$ and Peiris, 2008) for production of ethanol. At this step, yeast converts the carbohydrates into alcohol and $\mathrm{CO}_{2}$. Belal (2013) reported highest ethanol concentration (about 10 and 11 $\mathrm{g} / \mathrm{l})$ after 7 days fermentation with yeast (Saccharomyces cerevisae). A thermophilic yeast Kluyveromyces sp. IIPE453 can be suitably used for fermentation process. Kundu et al., (2015) reported that theoretical ethanol yield can be as high as $90.93 \%$ by simultaneous saccharification and fermentation (SSF) at the optimum conditions. Wang et al., (2015) has shown $77.3 \%$ increase in bioethanol production by SSF using a specific strain of yeast $S$. cerevisiae $\mathrm{KF}-7$ as compared with the $74.4 \%$ glucose recovery efficiency of enzymatic saccharification (Wang et al., 2015). However, microorganism e.g., Clostridium phytofermentans which can efficiently ferment cellulose (in the straw) directly to ethanol, may be considered as the most suitable candidate for ethanol production. Besides, the advent of genetically modified yeast and suitable synthetic hydrolysing enzymes may also improve bioethanol yield from rice straw.

\section{Fractional distillation and purification}

The alcoholic mixture referred to as 'mash' produced in the previous step is fed into a fractional distillation apparatus to separate the alcohol from other components of 'mash'. Further, the raw alcohol so produced is cleaned again following dehydration/drying process to remove water contents. The final product after a series of cleaning and drying process is the bioethanol with an extremely high purity of $99.7 \%(\mathrm{v} / \mathrm{v})$.

\section{Rice- a candidate crop for biomass production}

A kilogram of milled rice is produced against roughly $0.7-1.4 \mathrm{~kg}$ of rice straw depending on cultivars. On an average, $60 \%$ of a rice plant at maturity is straw, $14 \%$ constitutes bran and husk; while rest $26 \%$ is milled rice. Elevated $\left(\mathrm{CO}_{2}\right)$ significantly increased straw biomass (Zhu et al., 2016). Usually, landraces have lower rates of $\mathrm{CO}_{2}$ assimilation, increased transpiration via greater stomatal conductance, and a higher ratio of internal to atmospheric $\mathrm{CO}_{2}$ than advanced varieties. Stems constituted the largest component (34-55\%) of total dry biomass compared to leaf (23\%$37 \%$ ) and leaf sheath (23-33\%) (Jahn et al., 2011). Therefore, selection of thick tillers is necessary for high cellulosic biomass. Leaf traits, such as leaf thickness, size, and shape, 
leaf number, and orientation, plant height, tiller diameter, tiller length, tiller number, and straw girth are key factors influencing biomass formation (Yang and Hwa, 2008). Physiological traits related to growth and carbon capture, including leaf-area based photosynthesis, transpiration, stomatal conductance, and water use efficiency (WUE) can elucidate the process of biomass accumulation. In rice, erect leaves have a higher leaf area index that increases photosynthetic carbon assimilation rates through increased light capture and nitrogen use efficiency (Sakamoto et al., 2006).

Selection for high harvest index is expected to favour alleles that reduce vegetative biomass and favour grain yield. Hence, there is need to assess genetic variation and heritability of key traits that significantly impact biomass and the genomic regions associated with this variation. Biomass genetic variation in the OryzaSNP set can be a good option for biomass gene discovery. The dry biomass yield of Pokkali was about 11-fold higher than other low biomass varieties (Jahn et al., 2011).

\section{Genetic basis of cell wall components}

Paddy straw with high cellulose content results better saccharification yields. Genetic variation in saccharification yields do exists among rice cultivars (Abe et al., 2016) and thus, it will be a breeding target for biofuel production. Saccharification yield is high at tillering and before heading, but reduced after heading.

Stems show highest response at all growth stages while; leaf blades usually show lowest saccharification yields. Teramura et al., (2015) reported that the glucose content in the liquid hydrolysate is highly correlated with the resulting ethanol yield. So, glucose content can be considered as factor in selection of rice cultivars most suitable for bioethanol production. Goda et al., (2016) evaluated the natural variation of glucose content in dilute sulfuric acid pre-treated rice straws of 208 diverse cultivars. The glucose content varied across cultivars although largely affected by temperature. Hence, there is ample scope for development of novel rice cultivars for bioethanol production.

Recently, a novel mutant allele Osfc16 of cellulose synthase gene CESA9 showed normal plant growth with 25-41\% more biomass yield as compared to wild type (Nipponbare, a japonica variety) and the mutant enhanced enzymatic saccharification of biomass up to 2.3fold and ethanol production by $3442 \%$ (Li, 2017).

Reddy and Yang, (2006) reported a novel long natural cellulose fibre variant in rice with tensile strength similar to linen fibre. In contrast, Sharma (1986) isolated a brittle stem mutant of rice in which the so called parallel arranged cellulosic fibres are frequently broken resulting lower cellulose content. But, surprisingly, such mutants revealed higher hemicelluloses and lignin content than normal rice genotypes.

Cellulose fibrils are synthesized at the plasma membrane, whereas matrix polysaccharides (pectin and hemicellulose) are assembled in the Golgi cisternae and exported to the cell surface by Golgi-derived vesicles to form cell wall. Hemicellulose biosynthesis in the Golgi apparatus is mediated by seven GT (glycosyl transferases) gene families. On the other hand, Xie et al., (2011) identified sixteen QTLs for cellulosic fiber and lignin contents from an interspecific cross Oryza sativa $\times$ Oryza rufipogon. Most of the QTLs revealed small genetic effects and none of these were common in two environments suggesting significant environmental influence in biosynthesis of fibres. 
Fig.1 Chemical structure and composition of cellulose and hemicellulose of rice straw
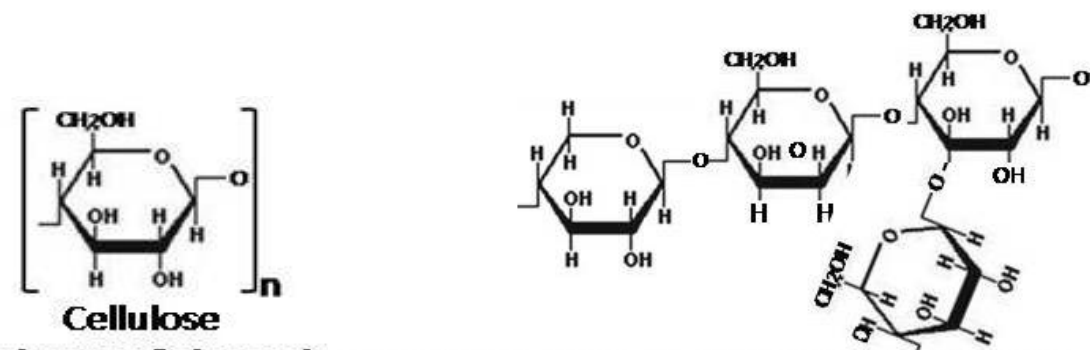

(polymer of glucose) Hemicellulose: -Xylose- $\beta(1-4)$ Mannose- $\beta(1-4)-G l u c o s e-\alpha(1-3)-G a l a c t o s e$

Fig.2 Effect of pre-treatment on lignocellulose complex
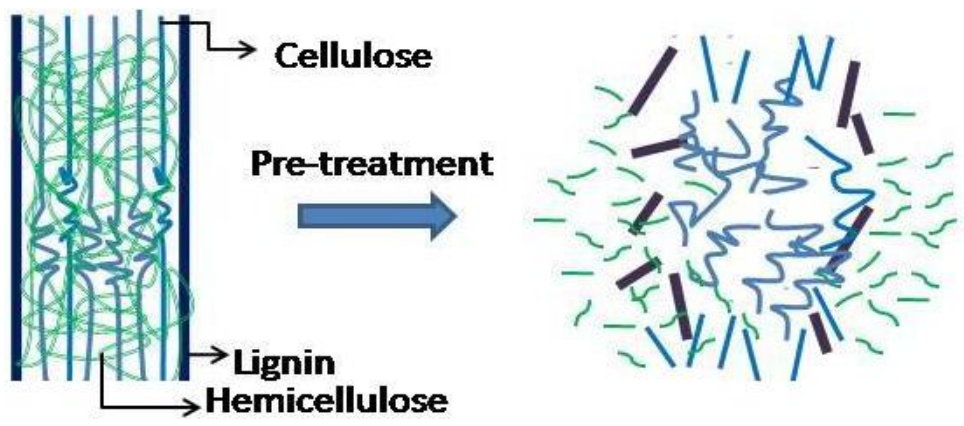

Fig.3 Enzymatic saccharification of cellulose (top) and hemicelluloses (below)

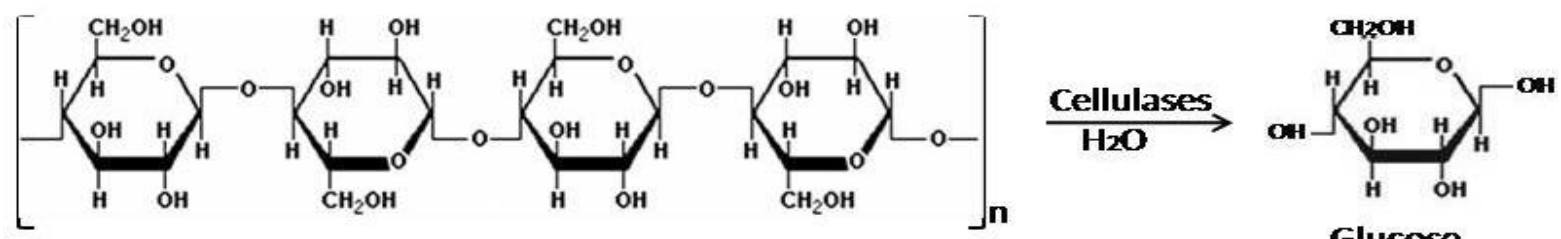

Hydrolysis of cellulose

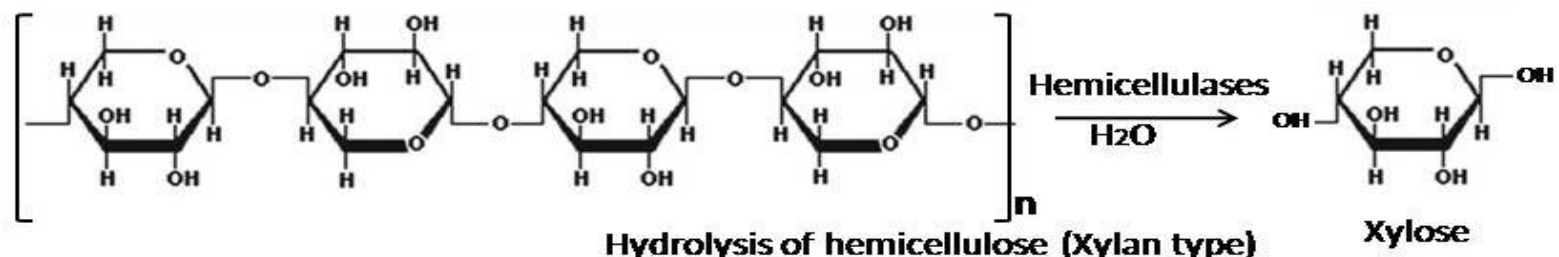

Further, they identified co-location of yield and fertility QTLs with those for fibre content within same marker interval in most of the cases which paves the way for development of dual-purpose rice varieties that are high in grain yield and are also high in straw quality.

Liu et al., (2016) developed recombinant inbred lines (RILs) from a cross between IR1552 (lowland rice) x Azucena (upland rice) and identified several cell-wall associated candidate genes using quantitative trait SNP (QTS) analysis using 271 molecular markers. One QTS locus and 4 pairs of epistatic loci had shown positive contribution to the enzymatic digestibility phenotype.

These loci revealed inverse relationship between reducing sugar and lignin content for aminability to enzymatic digestibility. The 
above QTS may be monitored using markerassisted breeding to develop high saccharification rice varieties.

Genotypic variation in lignin content in rice straw is reported to be ranged from 1 to almost $12 \%$ (Arai-Sanoh et al., 2011) although the estimated values largely differs between laboratories and method used. Ookawa et al., (2014) identified a natural long-culm rice variant with increased lodging resistance and low lignin (gh2) content amenable for bioenergy production. The gh2 locus is located in chromosome 2 and reduced synthesis of cinnamyl-alcohol dehydrogenase (CAD). Reduction of lignin in rice has been also achieved by RNA interference of the lignin biosynthesis gene Os4CL3 (Vanolme et al., 2010).

Genome wide association (GWAS) survey using high throughput SNPs can help to identify candidate genes (Wood et al., 2017) without complete elucidation. Mining the wide diversity of candidate genes associated with lignin and cellulosic fibre biosynthesis is now possible (Naz et al., 2017) using GWAS.

The analysis allowed us to identify regions of the genome containing significant associations between molecular markers and phenotypic data of the trait, but it is beyond reach for cell wall genes owing to difficulty in unbiased phenotyping of large number of genotypes using conventional analytical approaches. Recently, relative quantification of cell wall components has been made possible using carbohydrate microarrays and the technique could be suitably used for phenotypic characterization of genotypes. This paves the way for cell wall candidate gene identification through GWAS (Wood et al., 2017). Houston et al., (2015) detected a few putative cell wall candidate genes in barley that co-expressed with members of the cellulose synthase gene family.

\section{Exploring breeding strategy in rice}

Continued use of semidwarf varieties in conjunction with higher rates of nitrogen application has resulted in doubled grain yields. Seed yield usually negatively correlated with biomass and cell wall components. Modern high yielding cultivars are dwarf with moderately short erect leaves which reduce biomass yield. Cytokinin oxidase (OsCKX2) degrades Cytokinin resulting suppressed canopy growth and improved panicle characteristics and consequently increasing grain production in dwarf cultivars without lodging. Conversely, the tall indica rice varieties inherently results high biomass production with less partitioning of the same to the sink (low yield). A QTLbased strategy can improve lodging resistance even in tall plant types. In this context, it becomes a challenging task to breed a novel genotype with high grain yield alongside high biomass production. This can be achievable if the molecular mechanisms (genes) that regulate grain productivity, biomass production and aminability to its decomposition are critically elucidated. From productivity point of view, an ideal ideotype of rice should be intermediate in plant height with deep root system, moderate tillering, erect leaves, long heavy panicle, high grain number and resistance to biotic and abiotic stresses to improve yield potential. Rice varieties differ in composition and configuration of lignocellulose components. Rice straw with higher amount of cellulose in relaxed form (preferably less complexed with hemicelluloses) and low lignin content are most preferred for its easy decomposition and efficient ethanol production. The thumb rule is that the green plant stalks are more decomposable than the same after harvest. Hence, cultivars with stay green (SGR) trait will be rewarding. In wheat, functional stay green mutants maintained longer photosynthetic activity along with more seed 
weight and seed yield than the parent genotype. Post-flowering drought adaptation is reported to be associated with the staygreen phenotype in sorghum (Harris et al., 2007). The wild SGR allele (conditioning chlorophyll degradation by chlorophyllase) is expressed in green tissues and it is down regulated in leaves at post flowering stage causing senescence (Rong et al., 2013). Currently, a functional SGR mutant trait has been elucidated in japonica rice $(\mathrm{Fu}$ et al., 2009). Stay green rice cultivars retain green flag leaves and their stalks still maintain more water content even at physiological maturity. Such elite cultivars are expected to be high yielding with ease in decomposition of plant stalks.

Chlorophyll degradation by SGR gene (wild allele) is stimulated/triggered by $\mathrm{ABA}$ but inhibited by cytokinins (6-benzyladenine) (Park et al., 2007). Specific chlorophyllase gene(s) can be induced by methyl jasmonate and ethylene to stimulate chlorophyll breakdown similar to chlorophyll degradation under dark (dark induced senescence). Antisense suppression of a senescence related chlorophyllase gene in transgenic broccoli resulted reduced rate of post-harvest chlorophyll loss (Barry, 2009). Two separate stay green QTLs, one in flag leaf and other on penultimate leaf are co-located between flanking markers RM 455 and RM 505 on ch.7 and another two stay green QTLs specific to above respective leaves are colocated between flanking markers RM 410 and RM 566 on ch. 9. Besides, two other QTLs one on Chr. 5 and another on Chr.3 have been identified by molecular marker RM 440 and RM 228 respectively using single marker analysis (Yoo et al., 2007).

Rice genome being small in size (390mbp) and the genome has synteny with those of other cereals; it becomes a good candidate for molecular dissection and genetic transformation. Targeting of promoter sequence of cellulose synthase gene underlying cellulose biosynthesis is the direct approach to improve cellulose content using genetic transformation. Alternatively, the sucrose synthase gene Susy has been reported to improve the cellulose content in cell wall without any adverse effects on plant growth (Colman et al., 2009). Besides, enhanced photosynthesis under elevated $\mathrm{CO}_{2}$ is reported to increase total biomass and cellulose fibre production. Lignin in rice straw limits decomposition of plant stalks and follow-up fermentation. Down-regulation of genes involved in lignin biosynthesis seems to be a direct approach to reduce lignin content and alter lignin structure (Li et al., 2008). Xia (2013) reported silencing of $\mathrm{C} 4 \mathrm{H}$ (cinnamate4- hydrolase) gene using RNAi technique which reduced lignin content significantly with minimum effect on morpho-economic traits. Besides, identification of cell wall degrading genes and/or QTLs for reduced lignin content can be explored and suitably applied in marker-assisted selection (Frei 2013) for high ethanol yield.

Paddy straw is a better choice of substrate for ethanol production as it is structurally composed of higher amount of cellulose. This results better glucose yields by saccharification and follow-up efficient ethanol recovery by fermentation and purification steps. Development of dual purpose rice (high grain yield and high ethanol recovery) is a challenging task as straw biomass production and grain yield is often negatively correlated. Nonetheless, opportunities do exist to make it a reality by breaking yield barrier. Selection of high yielding rice varieties with moderately high biomass and low lignin, silica, ash and potassium content in straw are most preferred for accessibility of enzymes for saccharification. Besides, mining candidate genes for cellulose synthase, stay green trait 
and low lignin content in combination with exploring QTLs for high yield potential would certainly help breeders to develop bioenergy efficient smart varieties in rice using marker assisted selection.

\section{Acknowledgement}

We sincerely acknowledge and thank all researchers for their valuable contributions included in this pursuit.

\section{References}

Abe, T., Liyoshi, R., Ito, K., Takahashi, Y., Sato, K., Matsuzaka, A., Sonoki, T., Ito, Y. 2016. Difference of saccharification yields between organs and growth stages in rice. Plant Biotechnology, 33: 105-110.

Aderemi, B.O., Abu, E., Highina, B.K. 2008. The kinetics of glucose production from rice straw by Aspergillus niger. African J. Biotechnol., 7: 1745-1752.

Aderemi, B.O., Abu, E., Highina, B.K. 2008. The kinetics of glucose production from rice straw by Aspergillus niger African J. Biotechnol, 7: 1745-1752

Arai-Sanoh, Y., Ida, M., Zhao, R. 2011. Genotypic variations in non-structural carbohydrate and cell-wall components of the stem in rice, sorghum, and sugar vane, Bioscience, Biotechnology and Biochemistry, 75(6): 1104-1112.

Barry, C.S. 2009. The stay-green revolution: Recent progress in deciphering the mechanisms of chlorophyll degradation in higher plants, Plant Science, 176: 325-333.

Belal, E.B. 2013. Bioethanol production from rice straw residues. Braz J Microbiol., 44(1): 225-234.

Coleman HD, Yan J, Mansfield SD: (2009). Sucrose synthase affects carbon partitioning to increase cellulose production and altered cell wall ultrastructure. Proc Natl Acad Sci. USA, 106: 13118-13123.

FAO, 2014 FAOSTAT: Production - Crops 2012 data.
Frei, M. 2013. Lignin: characterization of a multifaceted crop component. Sci World J, 2013:436517.

Fu, J.D., Yan, Y.F., Lee, B.W. 2009. Physiological characteristics of a functional stay-green rice "SNUSG1" during grain-filling period. Journal of Crop Science and Biotechnology, 12(1): 47-52.

Fu, N., Peiris, P. 2008. Co-fermentation of a mixture of glucose and xylose to ethanol by Zymomonas mobilis and Pachysolen tannophilus. World J. Microbial. and Biotech., 24: 1091-1097.

Gaspar, M., Kalman, G., Reczey, K. 2007. Corn fibre as a raw material for hemicellulose and ethanol production. Process Biochem, 42: 1135-1139.

Goda, T., Teramura, H., Suehiro, M., Kanamaru, K., Kawaguchi, H., Ogino, C. 2016. Natural variation in the glucose content of dilute sulfuric acid-pretreated rice straw liquid hydrolysates: implications for bioethanol production. Bioscience, Biotechnology and Biochemistry, 80(5): 863-869.

Harris, K., Subudhi, P.K., Borrell, A., Jordan, D., Rosenow, D., Nguyen, H., Klein, P., Klein, R. Mullet, J. 2007. Sorghum staygreen QTL individually reduce postflowering drought-induced leaf senescence. J. Exp. Bot., 58 (2): 327-338.

Hon, D.N.S., Shiraishi, N. 2001. Wood and Cellulosic Chemistry (second ed.), Dekker, New York, p. 40.

Houston K, Burton RA, Sznajder B, Rafalski AJ, Dhugga KS, Mather DE, et al., (2015) A genome-wide association study for culm cellulose content in barley reveals candidate genes co-expressed with members of the cellulose synthase- a gene family. PLoS ONE 10(7): e0130890.

Huang, R.Y., Jiang, L.R., Zheng, J.S., Wang, T.S., Wang, H.C., Huang, Y.M., Hong, Z.L. 2013. Genetic basis of rice grain shape: so many genes, so little known. Trends Plant Sci., 18: 218-226.

Jahn, C.E., Mckay, J.K., Mauleon, R., Stephens, J., McNally, K., Bush, D.R., Leung, H., 
Leach, J.E. 2011. Genetic variation in biomass traits among 20 diverse rice varieties. Plant Physioloy,

Jin, S.B., Ja, K.K., Young, H.H., Byung, C.L., In-Geol, C., Heon, K.K. 2009. Improved enzymatic hydrolysis yield of rice straw using electron beam irradiation pretreatment. Bioresour. Technol., 100: 1285-1290.

Kim, S.B., Lee, S.J., Lee, J.H., Jung, Y.R., Thapa, L.P., Kim, J.S., Um, Y., Park, C., Kim, S.W. 2013. Pretreatment of rice straw with combined process using dilute sulfuric acid and aqueous ammonia. Biotechnol Biofuels, 6: 109.

Kim, T.H., Lee, Y.Y. 2007. Pretreatment of corn stover by soaking in aqueous ammonia at moderate temperatures. Appl. Biochem. Biotechnol., 137(1-12): 81-92.

Kundu, C., Lee, H.J. Lee, J.W. 2015. Enhanced bioethanol production from yellow poplar by deacetylation and oxalic acid pretreatment without detoxification. Bioresour. Technol., 178: 28-35.

Li, F., Xie, G., Huang, J., Zhang, R., Li, Y., Zhang, M., Wang, Y., Li, Y., Li, X., Xia, T., Qu, C., Hu, F., Ragauskas, A.J., Peng, L. 2017. OsCESA9 conserved site mutation leads to largely enhanced plant lodging resistance and biomass enzymatic saccharification by reducing cellulose DP and crystallinity in rice. Plant Biotechnol J., 15(9): 1093-1104.

Li, X., Weng, J.K., Chapple, C. 2008. Improvement of biomass through lignin modification. Plant J., 54:569-581.

Liu, B., Gómez, L.D., Hua, C., Sun, L., Ali, I., Huang, L. 2016. Linkage mapping of stem saccharification digestibility in rice. PLoS ONE 11(7): e0159117.

Lu, Z.X., Minoru, K. 1993. Effect of radiation pretreatment on enzymatic hydrolysis of rice straw with low concentrations of alkali solution. Bioresour. Technol., 43(1): 13-17.

Moubasher, M.H., Abdel-Hafez, S.I.I., AbdelFattah, H.M., Mohanram A.M. 1982. Direct estimation of Cellulose, Hemicellulose and Lignin. J Agricu Res.,
46: 1467-1476.

Mussatto, S.I., Roberto, I.C. 2004. Optimal experimental condition for hemicellulosic hydrolyzate treatment with activated charcoal for xylitol production. Biotechnol. Prog., 20: 134-139.

Naz, A., Reinert, S., Bostanci, C., Seperi, B., Leon, J., Bottger, C., Udekum, K.H., Frei, M. 2017. Mining the global diversity for bioenergy traits of barley straw: genomewide association study under varying plant water status. $G C B$ Bioenergy, 9: 1356-1369.

Ookawa, T., Inoue, K., Matsuoka, M., Ebitani, T., Takarada, T., Yamamoto, T., Ueda, T., Yokoyama, T., Sugiyama, C., Nakaba, S., Funada, R., Kato, H., Kanekatsu, M., Toyota, K., Motobayashi, T., Vazirzanjani, M., Tojo, S., Hirasawa, T. 2014. Increased lodging resistance in long-culm, low lignin gh2 rice for improved feed and bioenergy production. Scientific Reports, 4: 6567.

Park, S.Y., Yu, J.W., Park, J.S., Li, J., Yoo, S.C., Lee, N.Y., Lee, S.K., Jeong, S.W., Seo, H.S., Koh, H.J., Jeon, J.S., Park, Y.I., Paek, N.C. 2007. The senescence-induced staygreen protein regulates chlorophyll degradation. Plant Cell, 19:1649-1664.

Reddy, N., Yan, Y. 2006. Properties of highquality long natural cellulose fibers from rice straw. J. Agric. Food Chem., 54 (21): 8077-8081.

Rong, H., Tang, Y., Zhang, H., Wu, P., Chen, Y., Li, M., Wu, G., Jiang, H. 2013. The StayGreen Rice like (SGRL) gene regulates chlorophyll degradation in rice. J Plant Physiol., 170(15):1367-73.

Saha, B.C. 2003. Hemicellulose bioconversion Ind. Microbiol. Biotechnol., 30: 279-291.

Sakamoto, T., Morinaka, Y., Ohnishi, T., Sunohara, H., Fujioka, S., UeguchiTanaka, M., Mizutani, M., Sakata, K., Takatsuto, S., Yoshida, S. 2006. Erect leaves caused by brassinosteroid deficiency increase biomass production and grain yield in rice. Nat Biotechnol., 24: 105-109.

Sharma, U., Brillouet, J.M., Scalbert, A., 
Monties, B. 1986. Studies on a brittle stem mutant of rice, Oryza sativa L.; Characterization of lignin fractions, associated phenolic acids and polysaccharides from rice stem. Agronomie, EDP Sciences, 6 (3): 265-171.

Tabka, M.G., Herpoel-Gimbert, I., Monod, F., Asther, M., Sigoillot, J.C. 2006. Enzymatic saccharification of wheat straw for bioethanol production by a combined cellulose, xylanase and feruloyl esterase treatment. Enzyme Microb Tech., 39: 897902.

Taniguchi, M., Suzuki, H., Watanabe, D., Sakai, K., Hoshino, K., Tanaka, T. 2005. Evaluation of pretreatment with Pleurotus ostreatus for enzymatic hydrolysis of rice straw. J. Biosci. Bioeng., 100: 637-643.

Teramura, H., Sasaki, K., Oshima, T. 2015. Changes in lignin and polysaccharide components in 13 cultivars of rice straw following dilute acid pretreatment as studied by solution state 2D H-C NMR. PLOS One, 10: e0128417417

Vanholme, R., Demedts, B., Morreel, K., Ralph, J., Boerjan, W. 2010. Lignin biosynthesis and structure. Plant Physiol., 153: 895905.

Wang, G., Tan L., Sun, Z.Y., Gou, Z.X., Tang,.Q., Kida K. 2015. Production of bioethanol from rice straw by simultaneous saccharification and fermentation of whole pretreated slurry using Saccharomyces cerevisiae KF-7. Environmental Progress \& Sustainable Energy, 34(2): 582-588.

Wi, S.G., Choi, I.S., Kim, K.H., Kim, H.M., Bae, H.J. 2013. Bioethanol production from rice straw by popping pretreatment. Biotechnol Biofuels, 6: 166.

Wongjewboot, I., Kangsadan, T., Kongruang, S.,
Burapatana, V., Pripanapong, P. 2010. Ethanol production from rice straw using ultrasonic pretreatment. Int. Conf. on Chemistry and Chemical Engineering, 2010, (ICCCE), Kyoto, Japan, 1-3 Aug., 2010

Wood, I.P., Pearson, B.M., Garcia-Gutierrez, E., Havlickova, L., He, Z., Harper, A. L., Ian, B, Waldron, K.W. 2017. Carbohydrate microarrays and their use for the identification of molecular markers for plant cell wall composition. PNAS, 114(26): 6860-6865.

Xia, G. 2013. Repression of lignin synthesis in rice by $\mathrm{C} 4 \mathrm{H}$ and $4 \mathrm{CL}$ using RNAi. Int $J$ Biosci Biochem Bioinforma, 3: 226-228.

Xie, J.K., Kong, X, Chen, J., Hu, B., Wen, P., Zhuang, J, Bao, J. (2011). Mapping of quantitative trait loci for fiber and lignin contents from an interspecific cross Oryza sativa $\times$ Oryza rufipogon. J Zhejiang Univ Sci B., 12(7): 518-526.

Xiong, J., Ye, J., Liang, WZ, Fan, P.M.2000. Influence of microwave on the ultrastructure of cellulose: I. J. South China Univ. Technol., 28: 84-89.

Yang, X.C., Hwa, C.M. 2008. Genetic modification of plant architecture and variety improvement in rice. Heredity, 101: 396-404.

Yoo, S.C., Cho, S.H., Zhang, H., Paik, H.C., Lee, C.H., Li, J., Yoo, J.H., Lee, B.W., Koh, H.J., Seo, H.S., Paek, N.C. (2007). Quantitative Trait Loci Associated with Functional Stay-Green SNU-SG1 in Rice. Mol. Cells, 24(1): 83-94.

Zhu, C, Xu, X., Wang, D, Zhu, J., Liu, G., Seneweera, S. 2016. Elevated atmospheric [CO] stimulates sugar accumulation and cellulose degradation rates of rice straw. GCB Bioenergy, 8(3): 579-587.

\section{How to cite this article:}

Swapan K. Tripathy, Jayashree Kar, Bhaskar Chakma, Suraj K. Behera, Asit P. Dash, Arjun Prusty and Dayanidhi Mishra. 2018. Exploring Scope for Breeding of Rice Varieties for Efficient Ethanol Production without Compromising Seed Yield. Int.J.Curr.Microbiol.App.Sci. 7(05): 217-227. doi: https://doi.org/10.20546/ijcmas.2018.705.028 